\title{
The Spatial Morphology of Community in Chipping Barnet c.1800-2015: An Historical Dialogue of Tangible and Intangible Heritages
}

\author{
Laura Vaughan (1) and Sam Griffiths *(1) \\ Space Syntax Laboratory, The Bartlett School of Architecture, UCL, 22 Gordon Street, London WC1H 0QB, UK; \\ l.vaughan@ucl.ac.uk \\ * Correspondence: sam.griffiths@ucl.ac.uk
}

\footnotetext{
check for updates

Citation: Vaughan, L.; Griffiths, S. The Spatial Morphology of Community in Chipping Barnet c.1800-2015: An Historical Dialogue of Tangible and Intangible Heritages. Heritage 2021, 4, 1119-1140. https:// doi.org/10.3390/heritage4030062
}

Academic Editor: Éva Lovra

Received: 18 May 2021

Accepted: 17 June 2021

Published: 30 June 2021

Publisher's Note: MDPI stays neutral with regard to jurisdictional claims in published maps and institutional affiliations.

\begin{abstract}
This article presents a case study of the London suburb of Chipping Barnet to show how a spatial-morphological approach to tangible heritage challenges its archetypal image as an affluent commuter suburb by highlighting its resilience as a generative patterning of social space that has weathered successive phases of social change. We argue that the enduring spatial-morphological definition of Barnet as a local centre explains how it has been possible to preserve something less tangible-namely its identity as a suburban community. We show how Barnet's street network constitutes community heritage through a combination of local- and wider-scale affiliations that have sustained diverse localised socio-economic activity over an extended period of time. Noting how local histories often go further than sociological studies in emphasising the importance of the built environment for indexing the effects of social change on everyday life, we draw on a range of archive sources including the analysis of historical maps using space syntax techniques, to reveal Barnet's street network as a dialogue of both tangible and intangible heritages that are formative of a suburban community.
\end{abstract}

Keywords: Barnet; suburban centres; spatial morphology; heritage syntax urbanism; community heritage; tangible heritage; intangible heritage; space syntax

\section{Introduction}

The complex history of Greater London's suburban development is sometimes represented in culture as an essentially destructive process in which peripheral local communities were transformed into generic commuter suburbs by successive phases of railand car-based development. [1,2]. The conventional representation of suburbs in planning textbooks portrays them as functional expressions of the physical expansion of urban centres, with the corresponding increase in social and corporeal mobilities this signifies. The contrast between a lost—notionally local—past and the atomised suburban present that this image perpetuates may well be as ancient and resilient as that between town and country itself, a pervasive cultural distinction which the existence of suburbs only complicates (often to their detriment) [2]. British popular culture has tended to focus on the domesticity of the suburban home rather than the urbanity of the suburban centre, with the effect that suburbs as places with specific historical identities can seem barely to exist [3]. For all their ubiquity, or perhaps because of it, one might conclude that the suburbs are too much characterised by instability to have a distinctive built environment heritage, with the exception of cases where there has been the chance survival of historical sites, or the occasional example of architectural virtuosity amidst the swathes of unremarkable residential development. Yet, such an assumption stands contrary to the status of many suburbs as historically enduring communities with a recognisable spatial character [4].

This article presents research on the Greater London suburb of Chipping Barnet, located on the edge of Greater London, in the southern English county of Hertfordshire, 
sometimes known as High Barnet (and from now on referred to as Barnet) to offer an empirical account of what we call its spatial-morphological heritage. The purpose of the case study is to show how a consideration of the historical role of a street network in sustaining the socio-economic life of a suburban centre can help in defining what is at issue when considering 'ordinary' or 'everyday' heritage as an aspect of urban design [5]. The research seeks to arrive at recognisable empirical descriptions of an historical suburban landscape that is integral to the life of a contemporary community, rather than to draw attention to particular heritage sites that happen to be situated in Barnet. In a spatialmorphological sense, we are most interested in how the different aspects of the built environment are configured to sustain the characteristics of place.

Increasingly, built environment heritage policy is being developed using the broad contextual framing of historical urban landscapes (HUL) rather than the traditional emphasis on prestige historical sites of the kind that attract tourists [6]. Yet, there remains a problem of empirical description and delineation when it comes to conceiving of urban heritage in this wider sense [7]. This problem is even more acute with regard to the suburbs than with urban areas, despite the fact that many suburbs in the UK (including Barnet) developed from pre-industrial settlements with long histories as market towns. When suburban built environments are represented in culture as uniformly banal, it renders the everyday experience of the suburbs as generic and essentially alienating [8]. While social historians will always resist such simplifications of suburban history, their concerns are likely to remain marginal in policy arenas where there is a necessity for developing generic categories of description and delineation that can be applied to different kinds of historical urban landscapes. A spatial-morphological approach, which can be applied to any built environment, can make an important contribution to raising awareness of suburban heritage because it prioritises the formal description of everyday networks of public space ahead of the mapping of particular sites of local interest that are embedded within such networks. In this sense, it promises to assist with the task of offering generalisable definitions of historic suburban landscapes, while insisting that such characterisations have an empirical basis in the study of actual suburban places.

Space syntax theory and methods provide a way of conceptualising and representing the spatial morphology of settlements as dynamic encounter fields of socialising action [3]. Importantly, it regards the intangible, because largely ephemeral, practices of everyday life (such as movement and encounter) as emergent patterns shaped by the configuration and interfaces of the tangible elements of built environment heritage (such as streets and buildings). Karimi, for example, justifies his prioritisation of street networks in characterising the urban heritages of English and Iranian cities on the basis of their role in preserving the essential 'spatial spirit' of a city's street life [9]. This essential socio-spatial dynamic arises from the role of streets in generating the life of cities, for example by distributing pedestrian activity and urban land uses in an intelligible way [10]. Karimi's 'spatial spirit', one might say, describes the historical interplay of tangible and intangible heritages that constructs a sense of time in place. The way in which the material and immaterial aspects of built environment heritage implicate one another points to the fact that is the process of patterning urban life over time, rather than a particular quality of urban life at any given time, that is at issue in delineating historical urban and suburban landscapes alike.

A spatial-morphological focus on the role of street networks in sustaining predictable patterns of movement and land use recommends itself to considering how suburban centres might construct the spatial spirit of suburban places as a kind of community heritage. Everyday patterns of movement, spatial co-presence and encounter are implicated in giving rise to a shared experience of place and emplaced collective memory [11]. In the context of Greater London's suburbs, this has much to do with familiar spaces of sociability such as high streets that sustain a sense of temporal as well as spatial co-presence-that is a sense of the continuity of the life of the community in time, even while the membership of that community changes [12]. This quotidian dialogue of material and immaterial (or virtual) communities calls the simplistic opposition of past stabilities and present flux into 
question by acknowledging the ongoing role of streets in negotiating processes of change and continuity in London's suburban centres, and delineating an encounter field familiar to the many different kinds of people who live in them. It follows that the everyday routines of suburban places are not assumed to be fixed at any particular scale or orientation (though some may be more typical than others) but are equally likely to be formed in relation to other places at greater or lesser proximity to the centre itself. For example, in Greater London, many people either live and work close to home, or commute into, rather than away from, the suburbs every morning.

The notion of heritage syntax urbanism was proposed by Palaiologou and Griffiths to address the problem of identifying robust empirical descriptions of urban social space in the context of developing heritage policy [13]. It proposed: (a) prioritising a description that accounts for how the street network is configured as a globally connected system, rather than assessing the urban landscape's structure as if it were comprised of uniform and localised polygon shaped areas; (b) focusing on how streets contain varying patterns of social practices at different places within the local, urban, and regional network; and (c) characterising urban 'spatial culture' through a focus on how the characteristic patterning of community life is sustained through the intricate spatial variations within its built environment [14]. By bringing the perspective of heritage syntax urbanism to bear on Chipping Barnet as a particular suburban context, we hope to contribute to a humancentred and democratic definition of historic suburban landscapes that does not regard heritage as restricted to prestige urban centres or sites of special interest alone but as pervasive across all kinds of built environment that people value.

If contemporary Barnet is described by estate agents as a 'desirable' place to live, its origins were not so auspicious. It has been characterised by one historian as 'a messy and informal development of inn-keepers and traders locating on the heath, common-land, woods and pastures beside the highway ... ', rather than a 'planned street town' (see Figure 1) [15].

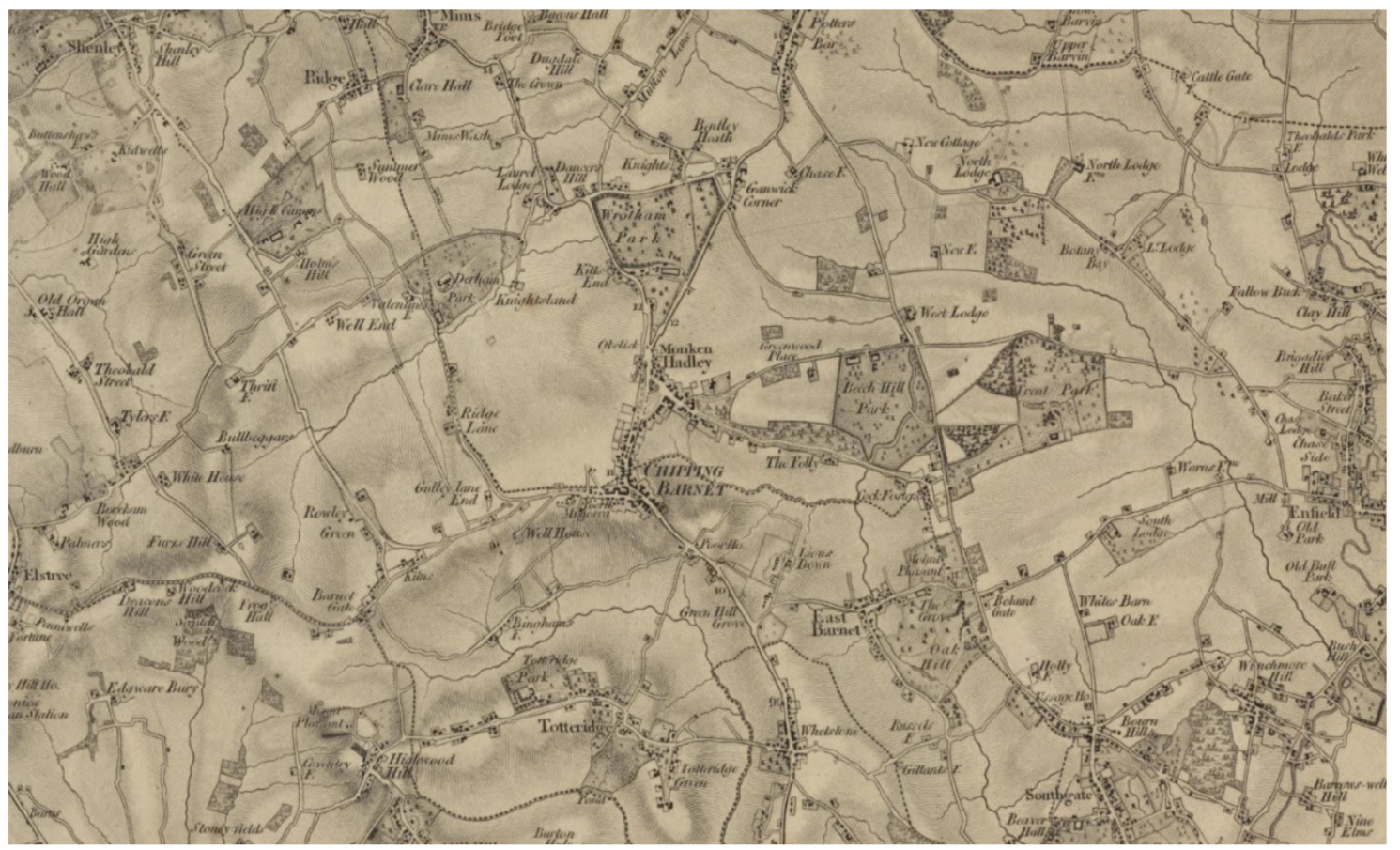

Figure 1. Ordnance Survey map of Barnet environs 1805-1873, courtesy http:/ / nla.gov.au/nla.obj-231917809/view (accessed on 14 May 2021).

Nowadays, Barnet is probably most likely to be regarded as a suburb of the capital at the end of the underground's Northern Line. Historically though, Barnet was defined by its situation on the Great North Road leading northward out of London that sustained 
its well-known market and hostelry. Unlike a railway network, a spatial configuration is not defined in terms of fixed origins and destinations because it also defines many in-between scales of movement. A major thoroughfare linking London to the north such as the Great North Road, for example, can equally be described and analysed as part of a local neighbourhood (Barnet), and as part of a regional network of suburban and small town centres. The history of busy roads is generally one of privileging their global (i.e., long-distance) connectivity by a systematic process of widening and straightening. Local centres necessarily resist this process of scale erosion, so far as they can. Indeed, their identity as local centres largely depends upon the quality of the localised street network to generate activity at socially meaningful scales that are differentiated from traffic passing through. While this effect can, to an extent, be stimulated through traffic calming, it is more robustly sustained by the spatial morphology of the suburban centre itself in constructing an interface between relatively localised and globalised patterns of movement. This implies pedestrians and vehicles of different kinds moving at different speeds, even while they may be sharing the same spaces [16]. We propose then, that the spatial spirit of Barnet is characterised by a hybrid spatial morphology that involves social affiliations constituted within and across spatial-morphological scales in an historical dialogue of tangible (built environment) heritage and the intangible (social-relational) quality of place.

\section{Barnet as an Historic Centre of Socio-Economic Activity}

Barnet was established as a market town by royal charter in the twelfth century. A combination of factors led to its successful functioning as a market town over many centuries. Its poor soil led its hinterland being used for woods, rather than agriculture [17], while its lack of rivers (pushing goods onto the roads), as well as its location a convenient day's travel from London, meant that it became one of a ring of markets used by 'dealers and drovers from farther afield' to sell onto City traders [18]. The result was a market town located in a strategic position on the Great North Road. Its subsequent plot development followed the demands of trade, with subdivisions derived from previous pasture patterns and roadside adjacencies.

While none of the Hertfordshire's towns gained primacy over the centuries, historians agree that a number of geographical and political factors contributed to Barnet's success. Its situation at the intersection of parish boundaries meant that it not only benefited from increased trade for its market, but also that it did not suffer from the control of a single manorial overlord. This jurisdictional complexity meant that its 'merchants, craftsmen and traders' escaped regulation by a dominant landowner [op cit]. Barnet's accessible location on the Great North Road meant that its market benefitted from regular traffic through the town, while its proximity to London resulted in it serving as a trading post, a way-station at a convenient distance away from the city, and a processing centre for supplying the capital's needs for products such as meat, leather and cheese [op cit]. Together, these characteristics meant that Barnet's occupational diversity evolved over an extended period of time and contributed to its economic resilience.

The socio-economic life of Barnet has been historically constructed over distance, though the nature of these connections has changed. Long before it became a suburban centre, for example, it was home to a Militia Barracks for Middlesex regiments and a weekly cattle market that supplied London with much of its meat c.1600-1950. On the other hand, Barnet's public architecture from the 1700s into the early twentieth century points to the existence of a strong sense of locality and status as the administrative centre of various civic jurisdictions. Barnet's history has therefore been forged historically both spatially, in relation to people living or working in its vicinity, and across space, in relation to the surrounding counties and London. At one time, over a hundred and fifty mail and stagecoaches, besides post-chaises, private carriages, wagons, \&c., passed daily through the town $[19,20]$. Samuel Pepys mentions travelling by coach from the City via Barnet, taking the waters at 'the Well' [21], and travelling on to visit Lord Salisbury at Hatfield, returning back to a friend's lodging for a meal. The anecdote illustrates perfectly how 
Barnet served both as link and place in the street network [22]. Similarly, Cary's 1790 Survey of the High Roads from London illustrates the importance of the Great North Road in connecting Chipping Barnet to Welwyn via Hatfield [23]. (Figure 2). Subsequently, Barnet was connected to St Albans to the north-west and via the Great Northern Railway and then the London Underground into central London. One might say that this remarkable connectivity is no less a part of Barnet's heritage than its market and civic buildings-and indeed the two things are related.

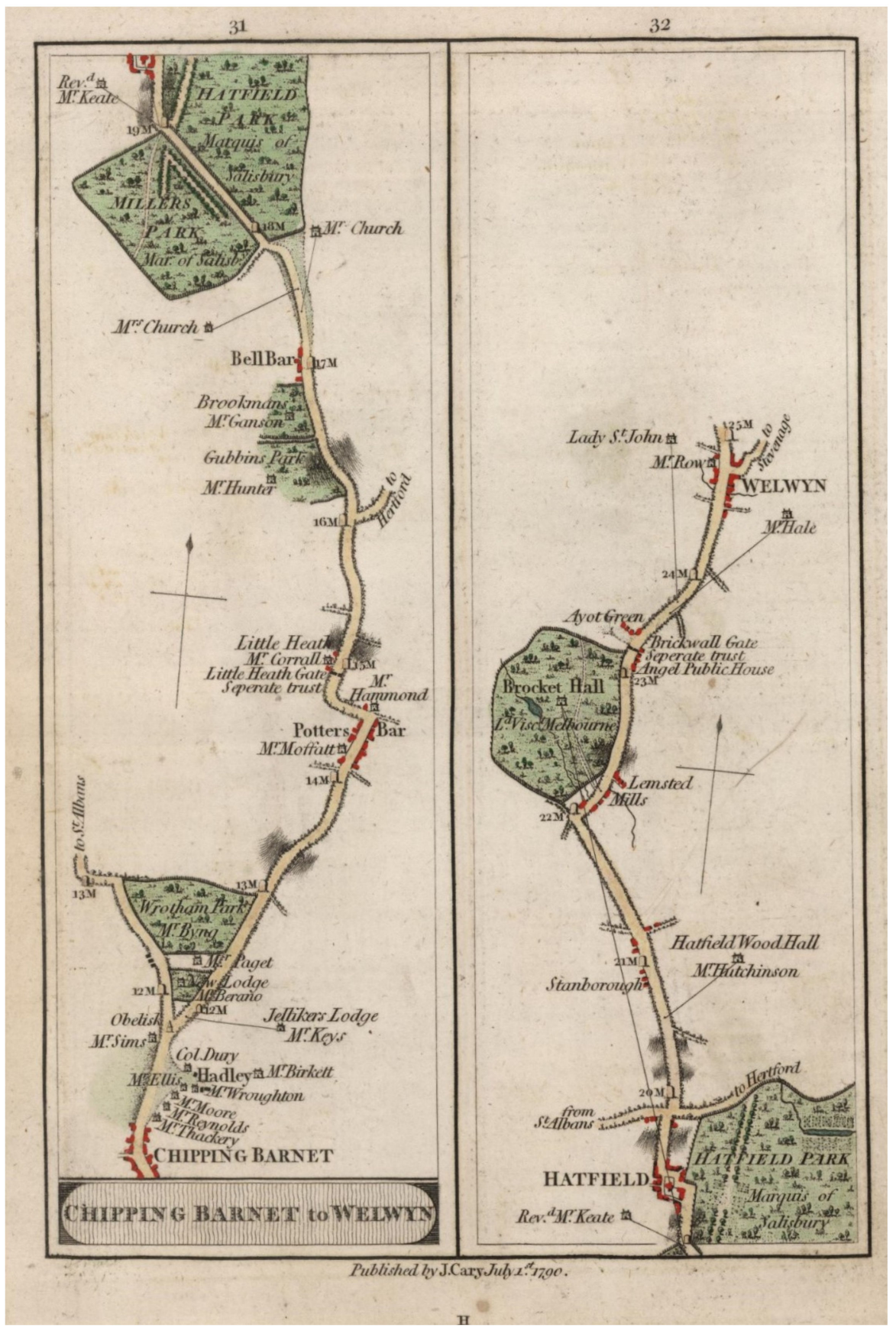

Figure 2. Chipping Barnet to Welwyn, London to Hertford. 1790, from Cary's 1790 Survey of the High Roads from London (see [23] for full citation).

Transformations in transportation technology: roads, tolls, mail services, and trains have intensified connections between and across the social spaces of Barnet. These sorts of generative connections have tangible manifestations on the ground: for example, in 
the spatial alignments of the road network that directs traffic through Barnet, and in the eighteenth- and nineteenth-century buildings that indicate affinities extending beyond the historic town, such as the alms-houses for the City of London's Leathersellers' Company. Other historic structures mark boundaries, such as tollgates, inns and road junctions, while temporary structures, such as the weekly market, which though now a sad remnant of its recent past, still represents a continuity with centuries of market activity.

It is interesting how local histories often do better than more sociological studies in reflecting on the curious admixture of change and continuity that characterises suburban life. These tend to be less concerned with the chance survival of heritage buildings than with the relatively unphotogenic high street shops that are offered as indices of change and continuity in the collective memory of the community. Although rarely the focus of explicit reflection, these characteristic photographs and postcards pose interesting questions regarding this continuity from the past into the present. The simple fact that such images remain on sale in local shops suggests a degree of value is placed on acknowledging the balance of historical change and continuity in Barnet as a community [12].

The postcards of Barnet High Street (see Figure 3) indicate the presence of a persistent spatial culture of social and economic life focused on a linear high street that has been in continual use for at least several centuries [24]. This poses an historical question. It would be no more correct to state, for example, that Barnet is an idyllic chocolate-box suburb (perhaps featuring a rose-garden Edwardian cottage or even the apparently carefree affluence of the popular 1970s sitcom The Good Life), as it would be to say that its individual identity has been dissolved into Greater London. Labels such as 'suburb' are not necessarily helpful in heritage contexts since they carry a cultural freight that leads us ultimately to questions of what the suburbs mean in a rather intellectual sense, rather than what it is that people most value in suburban built environments.
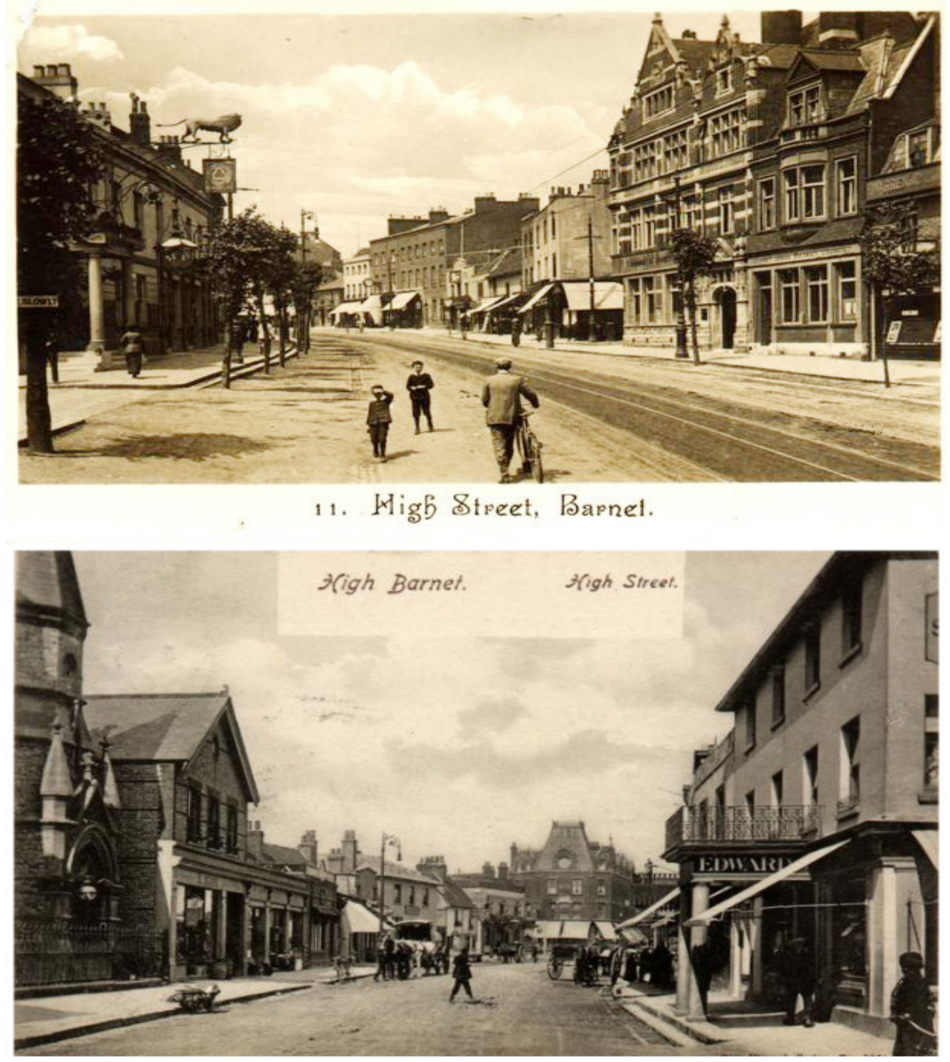

Figure 3. Postcards of High Barnet.

In contrast with Barnet's regionally connected road network, its civic infrastructure has largely maintained the historical spatial boundaries of its situation on the edge of the 
London which distinguishes it as a place with its own identity. Institutional buildings relating to jurisprudence (a local magistrates court, now closed), ecclesiastical functions (a parish church), and law and order (a militia barracks that housed the seventh battalion King's Royal Rifle Corps, today the headquarters of the 151 Regiment and Territorial Army recruitment centre) all speak to a tradition of significant civic autonomy that reached its high point in the late nineteenth century. Although such institutional autonomy is largely historical it also suggests why, in heritage terms, the suburbs do exist! While Barnet's suburban civic architecture might not be remarkable, it stands testimony to the spatialmorphological resistance of the centre to being identified entirely with its location on the Great North Road. If local institutional autonomy may be degraded in the contemporary political context, the local street network, established centuries before, sustains the sense of Barnet as a distinct centre.

Of course, there have also been changes in urban planning regulation that affected the historic street network of Barnet in the modern era. In Barnet's case, there have certainly been positives. The twentieth-century Green Belt, by interrupting development within its vicinity, has played an important part in preserving something of the 'spatial spirit' of the historical settlement. All in all, it seems justifiable to propose the spatial morphological 'signature' of Barnet's suburban centre as the defining feature of its tangible heritage [25]. In the following analysis, we will describe the process of Barnet's spatial development over time in order to relate this spatial-morphological definition of suburb to its enduring life as a community.

\section{Materials and Methods}

Slater has pointed out that closer scrutiny of the supposedly 'simple' plans of Hertfordshire reveals how the urban landscape has been shaped by a combination of factors over time, a temporal dimension that also belies the almost meaningless designation of non-grid street networks as 'organic' [26,27]. Whitehand has emphasised the importance of plan analysis for its providing a framework for studying 'the relationship between plots and the block plans of building' [28]. Whitehand's account of M. R. G. Conzen's classic analysis of plot development in the English town of Alnwick was an important influence on our own work in its emphasis on how the boundaries and dimensions of plots, and particularly the shifts in frontage length and footprint size over time, drive spatial change in a given location. Conzen describes the temporal cycle of progressive in-filling of buildings on plots until they reach capacity and fall fallow as a process of morphogenesis. Conzenian analysis informed our focus on the interrelationship between buildings, their uses, and the characteristics of the streets on which they sit. Yet, there is a danger that an emphasis on defining boundaries according to their local plot-building characteristics, can lead morphogenetic descriptions to understate the influence of the global street network in sustaining centrality 'as a process' that re-produces the essential messiness of lively places [10]. Thus, without a configurational account of the historical street network, planners or heritage experts may struggle to challenge the largely functional planning designation of suburban space, as it does not give due regard to the importance of the encounter field as generative source of community life and spatial culture [13].

The mapping of Barnet's built environment in time-series using historical cartographic sources from Ordnance Survey (c. 1880, 1910, 1960, 2013) and linked to land-use data from business directories linked in GIS (Geographic Information Systems) made it possible to think in detail about the balance of change and continuity that, we argue, is relevant to a characterisation of the 'spatial spirit' of Barnet as a local place-a quality which is difficult to explain on the basis of more qualitative indices alone. By mapping the development of the road network from the nineteenth century, we can offer a different perspective on simplistic narratives of peripheral suburban growth to consider how a locale such as Barnet functioned both as place and a link between places at different scales of movement. The emergence of these kinds of multi-scaled high-street spaces may well be the defining characteristic of historic suburban landscapes. 
Quantitative descriptions of urban street networks using space syntax have been deployed by scholars of history and architecture alike to formulate hypotheses regarding the use of urban and suburban places in the past [29]. When applied to the history of Barnet, space syntax methods find the tension between the centre's socio-economic accessibility to the surrounding region and the aggregation of place-bound (or localised) activities to be reflected in the way in which Barnet's street network has evolved over time. The configurational analysis of street networks produces detailed quantitative descriptions (and visual representations-see Results section) that can help explain how a given street may simultaneously sustain multiple activities by facilitating movement at a variety of scales and bringing them into spatial co-presence: from the micro-morphology of local socio-economic activity to the regional scale of inter-urban transport mobilities.

A detailed account of the space syntax method deployed in a suburban built environment is available elsewhere [16]. For our present purpose, it is sufficient simply to state that the method takes the town plan or map and translates it into a computer-based representation of the street network as a pattern of accessibility. This is used as the starting point for empirical research into the historical relationship between urban space and urban life by analysing each street's connections to all other streets and how these change over time. Space syntax research views streets in configurational terms as a differentiated system of connected, habitable, spaces. The analysis allows us to compute with great precision the relative centrality of all the streets in the system, and from this to estimate with some certainty the patterns of pedestrian use they might have sustained. These estimates can be cross-referenced with other forms of historical data such as land-use patterns, since certain land uses (most notably retail) are likely to favour locations with high footfall.

Our purpose here is to examine the validity of the proposition that while successive phases of growth in and around Barnet may have eroded and displaced the typical scale of everyday life in the historical settlement, a proper understanding of this process should not simply be in terms of periodic erasure, implying a deterministic narrative of sequential change from outlying market town to commuter suburb. Rather, the spatial-morphological analysis develops the proposition that social change is not necessarily a question of an accumulation of layers, but involves the complex material entanglement of old and new social practices. Our analysis intends to assess how far these practices can be identified in the description of the varied affordances of Barnet's quotidian spaces in the spirit of Michael de Certeau's proposition that 'space is a practised place' [30]. Heritage, in this sense, is regarded as a dynamic legacy of historical settlement forms, rather than a passive remnant of another way of life.

This perspective on spatial morphology as a dialogue of tangible and intangible heritages can help explain how residual local social activities such as bumping into neighbours that were likely to have been familiar to our eighteenth-century ancestors may persist and even feed into building global communities of interest on contemporary social media platforms [31]. At the same time, other activities (e.g., chairing a work meeting for clients of a central London firm, while working from home on a broadband connection) assume work practices and a telecommunications capability barely conceivable even in the late twentieth century, yet find ways of re-using much of the same built environment infrastructure. In Barnet-one can speculate- this might involve adapting the interior of a Victorian terrace house to accommodate a home office (a necessity forced on many people in the current pandemic), with its situation off the pre-urban main road giving easy access to footpaths onto the high street, allowing inhabitants to pop out for a coffee during their working day. Thus, the adaptability of the historical infrastructure makes it possible to sustain contemporary social practices. The effectiveness of new infrastructural interventions is, to an extent, dependent on how well they accommodate to this historical legacy. The local-to-regional accessibility of Barnet allows us to characterise the town's varied relationships over closer and greater distances through time. It follows that defining suburban heritage requires both recognising and describing the spatial-morphological signatures of communities that have adapted to successive phases of social change; enquiring what made such resilience 
possible, to the extent that this is the case. In this sense, the heritage of Barnet as a suburban place is not simply something that is, it is something made and remade.

While maps are useful sources for the spatial-morphological analysis of the urban past, the analysis of business directories allows for a snapshot on non-domestic activities in a town centre. It is important to emphasise the gaps in this dataset: small businesses, especially those that could not afford to pay for an entry, and frequently those run by women, were more likely to be omitted and in general, these are less comprehensive on economic value than rate records. However, for the purpose of complementing information on building form and plot layout, and particularly when studying a large area historically, data on land use patterns from business directories can be highly revealing of the economic character of a place through time (see Figure 4). Our study obtained data from Post Office Trade directories and Kelly's London Suburban Directories for the periods 1874, 1914, 1969 and, for the contemporary period, from the Ordnance Survey c. 2014. These data were transcribed and classified to fix the entries to the nearest street segment (the section between two junctions) and, where possible, were geocoded to a specific location using an Ordnance Survey map from the most closely corresponding period. Land uses were classified according to contemporary standard types that amount to 25 uses in 5 broad groups (see legend for Figure 8, below).

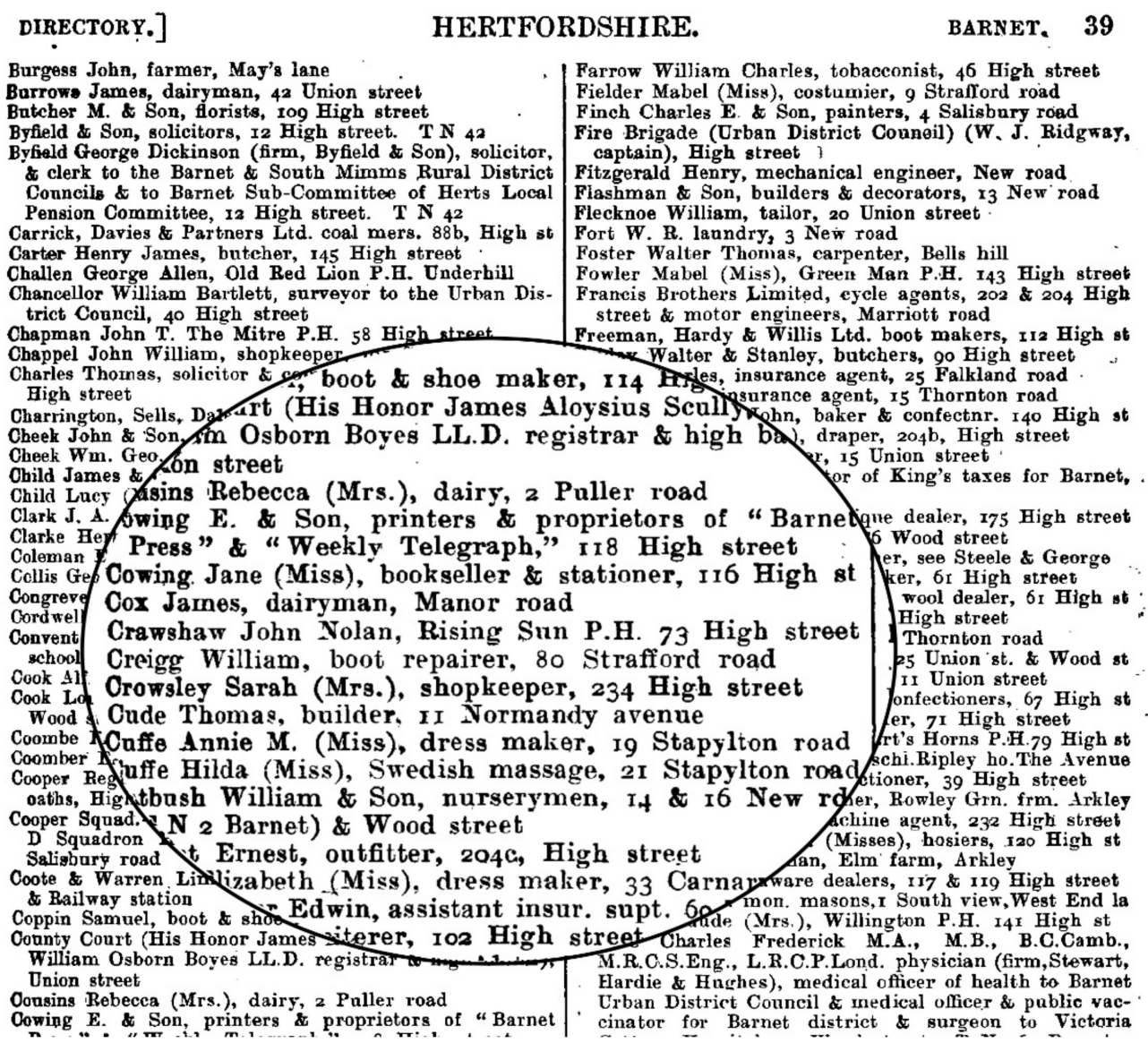

Figure 4. Sample page from listings for Barnet, in Kelly's Post Office Hertfordshire business directory, 1914. London: Kelly's Directories, pp. 32-41 (with inset of a magnified section).

\section{Results}

It is evident from the historical account provided above how the pre-industrial era genesis of the street and road network surrounding Barnet-together with local patterns of land ownership - established subsequent trajectories of development that give spatialmorphological definition to the suburb's heritage. Slater notes how 'the properties which 
line both sides of High Street and the south side of Wood Street clearly derive from the roadside ends of earlier pasture closes... Barnet's plan therefore quickly achieved an urbanity to match that of other market towns' [29]. This suburban urbanity is evident also from a simple figure-ground analysis of the town, as seen in Figure 5 (refer also to Figure 1 for the earlier map of the area), which highlights the spatial dominance of Barnet within its vicinity c. 1880, even when compared to East Barnet, apparent in the south-east edge of the map.

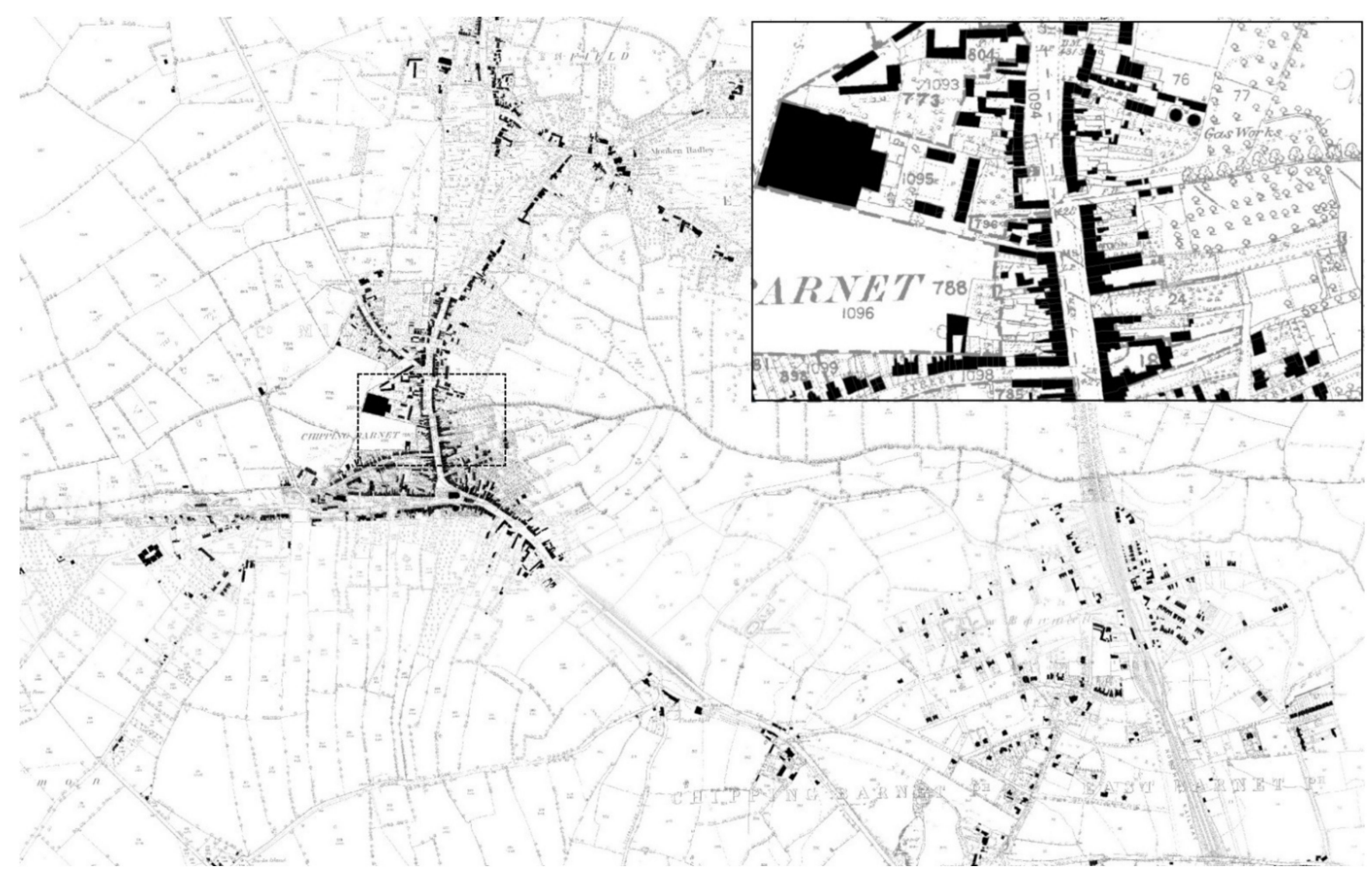

Figure 5. Figure-ground map of Barnet and environs c. 1890, with inset showing high street at scale 1:1000. Created using "Old Map of Hertfordshire”, [BMP map], Scale 1:10,560, Ordnance Survey County Series 1st Edition published 1865-1894, (c) Crown Copyright and Landmark Information Group Limited: Edinburgh (2010), UK. Using: EDINA Historic Digimap Service.

A systematic study of movement flows using structured video observations of a large range of streets in the area during the working day was conducted by the authors' research team approximately one decade ago. It found two distinct groups dominating the high street area during the working week. The first was those out with a purpose; these were often young mothers and-significantly-those working in the town centre, out running errands or for meetings in local cafes. The other group were in the town centre as browsers, and were typically the elderly and the young alike, who used the town centre as a way to spend leisure time. By the evening rush-hour, many casually dressed pedestrians were observed entering the underground station from the centre, suggesting once more that commuters do not dominate this town. The restaurants and bars were also starting to fill up, indicating a night-time activity.

The space syntax analysis presented in Figures 6 and 7 was originally undertaken for an extensive study into London's evolution from 1890 to the early twenty-first century [32,33]. It shows how Barnet continued to expand throughout the nineteenth century, with significant intensification having taken place by 1890 as a consequence of residential 
expansion around the railway station. It is evident from a space syntax analysis of the development of Barnet's built environment from 1880 to the present time how Barnet High Street retained its centrality despite the extensive expansion in the built-up area and intensification of the road network during the period. Figure 6 shows the time-series sequence of maps of the area during four periods. The configurational analysis considers each street segment's connections to all other segments within a six-kilometre radius, resulting in a table of numeric values displayed here as a spectrum from red to blue. While the principal route running through the town centre is the Great North Road (named High Street for the sections within the town's built-up area), it is also important to note that in the most recent period the impact of the peripheral M25 motorway is visible (on the north-west edge of Figure 6). This results in a shifting of peak centrality from the high street to the road sections linking it southwards towards London.

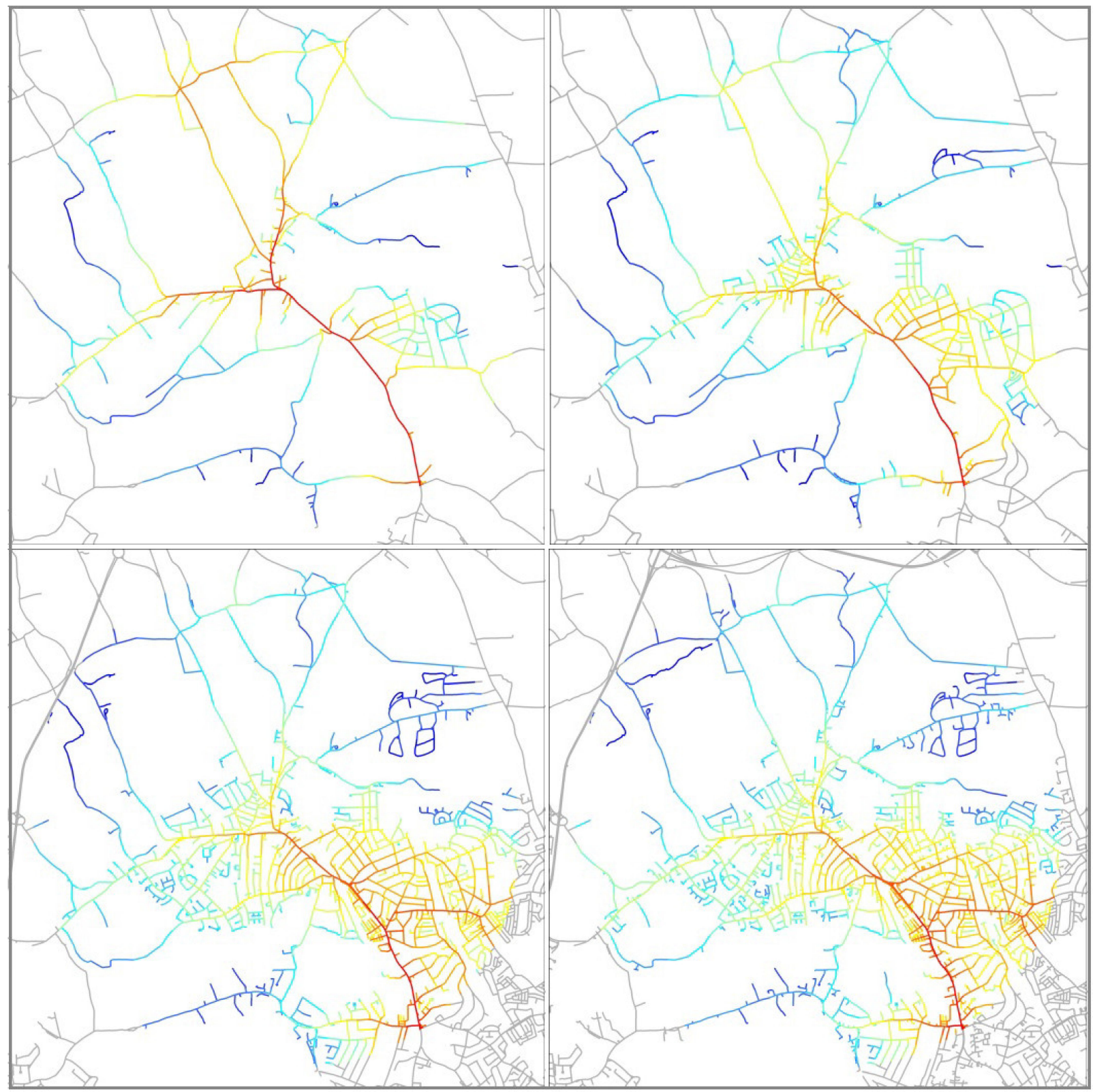

Figure 6. Barnet and environs c. 1880, 1910, 1960, 2013, (top-left) to (bottom-right), respectively, analysed according to their potential for movement through the area, measuring relative centrality for routes at a distance of $3 \mathrm{~km}$. The warmer the colour in a spectrum from red to blue, the higher the predicted centrality. 


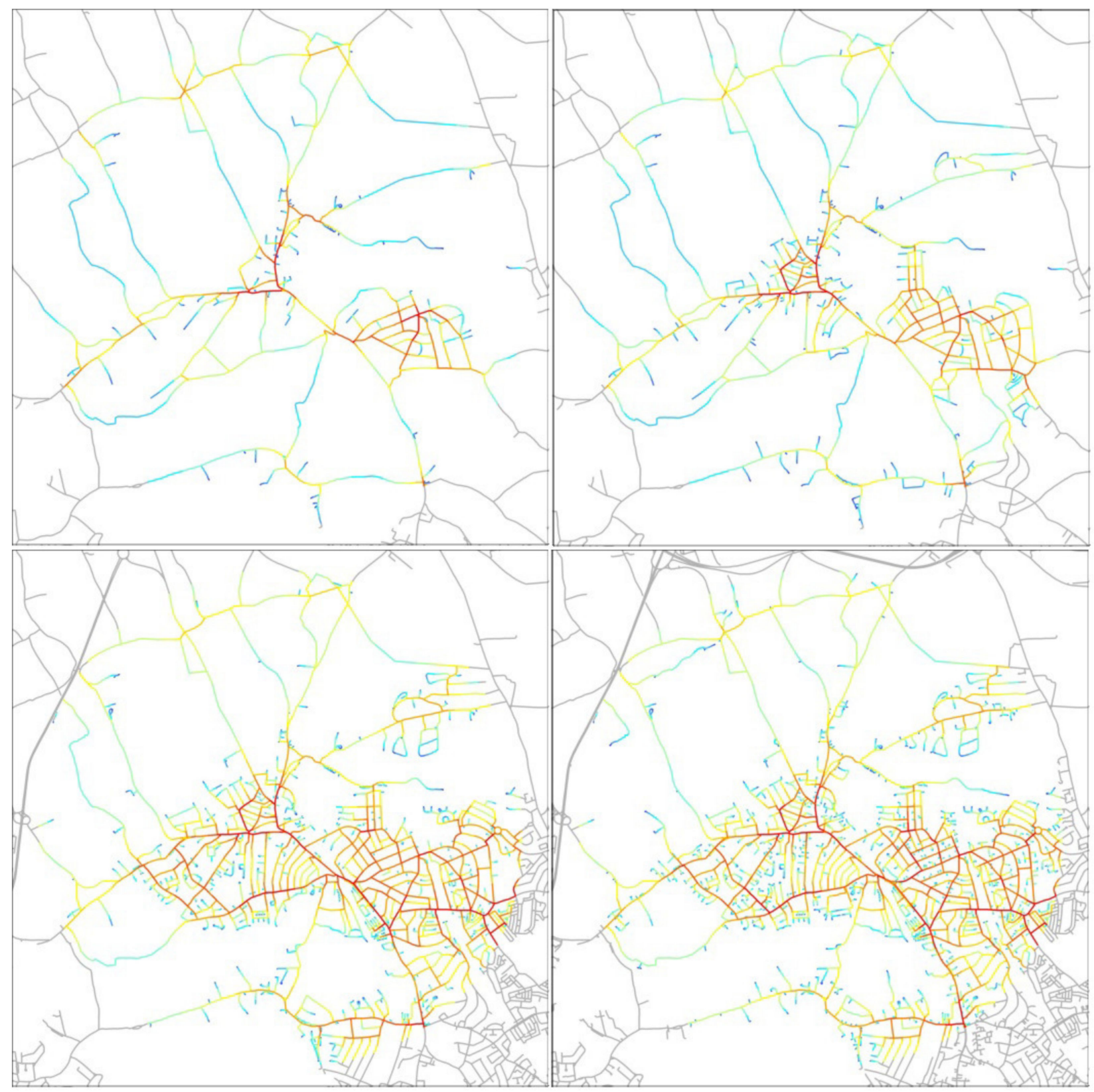

Figure 7. Barnet and environs c. 1880, 1910, 1960, 2013, (top-left) to (bottom-right), respectively, analysed according to their potential for movement to each street the area, measuring relative accessibility for routes at a distance of $800 \mathrm{~m}$, approximating a $10 \mathrm{~min}$ walk. The warmer the colour in a spectrum from red to blue, the higher the predicted accessibility.

A different sequence of maps considers the same area for its local accessibility. Figure 7 shows the streets coloured in a range from red to blue, indicating how accessible each street segment is for local connections to/from approximately 800 metres away. It is evident that whether considering only its local connections, or its local-to-global connections through its high street to other places, Barnet possesses what Hillier termed 'pervasive centrality'. This refers to the network connectivity of centres at all scales, some smaller and some larger, with Barnet's high street and to a lesser extent Wood Street (the red-coloured alignment running east-west on the in the model) maintaining a constant prominence in the upper bands of connectivity [34,35]. Hillier argued that the way in which local centres fit into a pattern of connections at different scales reflects the potential for those connections to support flows of movement across different distances. This is not purely a matter of absolute distance measured in meters or kilometres, but what he referred to as 'intelligible 
distance', namely the intricate linkages from footpaths to streets to roads and thoroughfares that together form an emergent, and highly intuitive, pattern of connectivity over time. This does not, of course, mean that such a network structure transcends historical events. On the contrary, the argument is that the deep structure of historical road network is able to accommodate a large number of localised changes, while changes at the scale of the network itself are relatively gradual and infrequent. In this respect dramatic large-scale interventions in the road-network such as ring-roads and bypasses are the exceptions that prove the rule - even here the resilience of the historical street network is often remarkable. This emergent spatial configuration sustains patterns of accessibility over time. It adapts to periodic shifts in road connectivity as well as local changes to building shapes and layouts, and it mediates social changes that mould the 'spatial spirit' of place [35].

The analysis shown in Figures 6 and 7 indicates how the network of footpaths, streets and roads connects from the residential areas of Barnet through to the high street, with the most prominent street segments being continuously accessible from the past to the present. This means that even today, when the district has many of its inhabitants commuting out of the area, the street network continues to support local circulatory trips around the centre, whether it is to pass the time of day, to be sociable, or to go to work locally. Indeed, the evidence from observations made in the field, and census data on commuting patterns, both sustain this pattern of behaviour [36]. The result in Barnet is a suburban centre that can maintain its vitality both economically and socially, despite the town's social and economic character having been transformed over the past century and more. Even today we can see small business premises and workshops situated to the rear of the high street, meaning that the people using the area are not just local inhabitants-but also include people working and visiting the area.

If one were to focus purely on the land uses along the section of the high street north and south of today's semi-enclosed shopping centre, The Spires, it would be possible fall into the trap of describing Barnet as an example of 'Clone Town Britain'-to adopt the pejorative terminology of the New Economics Foundation (NEF) [37]. Yet, the Ordnance Survey database finds businesses ranging from two national supermarkets, two national opticians, one each of a national chain of hairdresser's and opticians alongside a relatively small number of independent or local chains of bakery, clothing and cash converters. If we analyse a more representative sample along the high street the picture shifts dramatically. Figure 8 shows the contemporary land uses along the full length of the section of the Great North Road that is named High Street. The buildings are coloured according to their land uses, shaded according to 25 possible categories, with additional shading for mixed uses. The land uses classification is placed alongside a space syntax analysis of integration at a local $(800 \mathrm{~m})$ and larger scale $(3000 \mathrm{~m})$. A comparison of these figures reveals how Barnet's street network comprises a spectrum of street segment characteristics associated with both high levels of pedestrian and vehicular movement at different scales (including both highly localised patterns of pedestrian intensive circulation which serves as an attractive destination for trips over longer distances). These complementary configurational qualities sustain different categories of land use in Barnet's town centre. Even such a relatively detailed land use classification though, is incapable of emphasising the diversity of specific uses, which comprises independent estate agents, a local chain of hairdressers, dry cleaners, a number of independent as well as chain restaurants and coffee shops, banks, independent jewellers, and both independent and chain chemists and bookshops. Even at the time of writing, a year into the global pandemic, new land uses are emerging, such as a florist's offering local deliveries during lockdown. The continual churn of commercial land uses preserves as much as it displaces. The discovery in 2020 of a fourteenth-century building concealed behind the façade of an apparently unremarkable shop unit (a hair salon being refurbished as a florist) is an interesting example of an intersection between the everyday heritage of the suburban high street and the high status heritage represented by important historical buildings. In this case, it is unlikely that the latter could have survived in the absence of the former. 


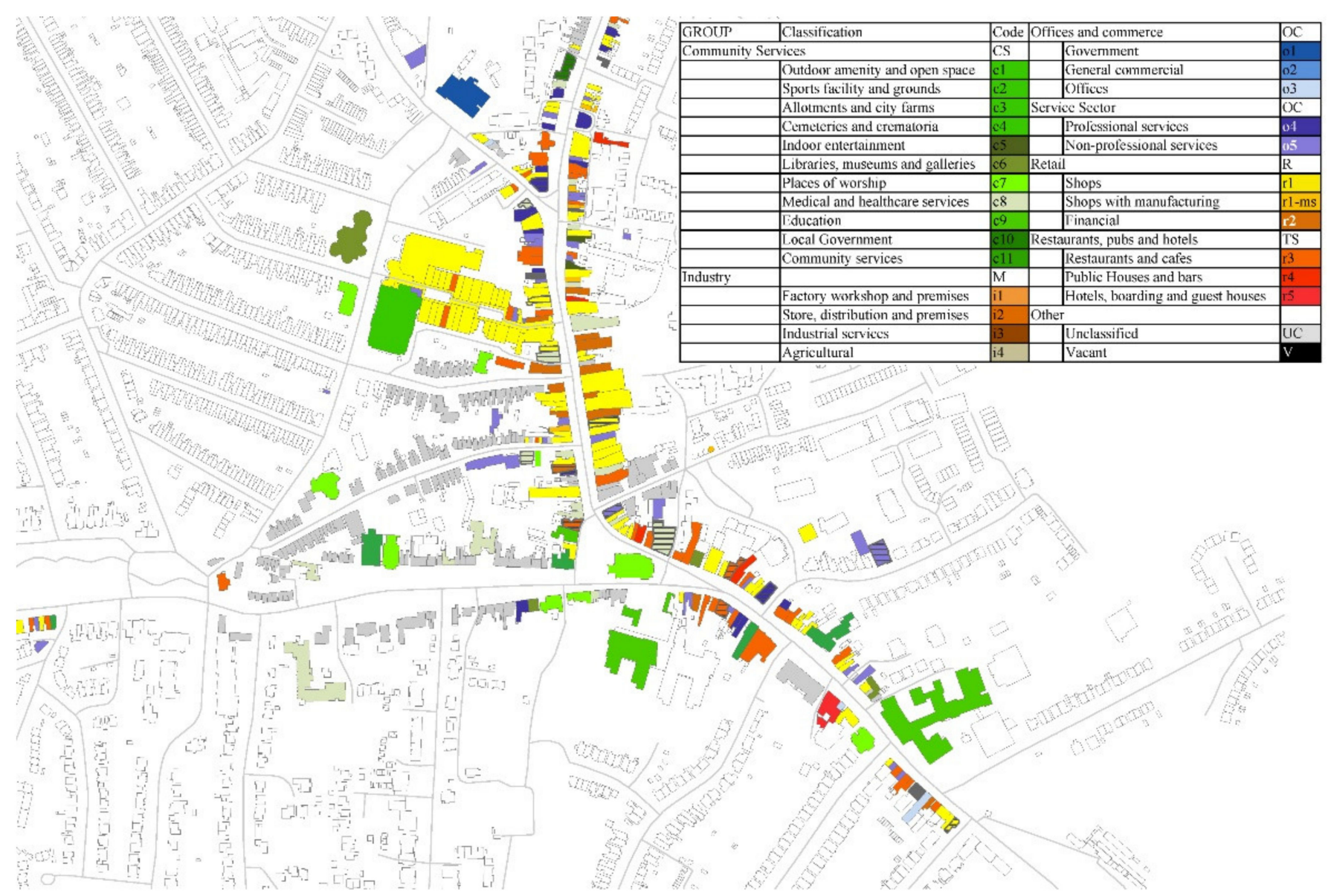

Figure 8. Land use classification for High Street Barnet, c. 2013. Refer to Figures 6 and 7, (bottom-right), for spatial analysis of the contemporary map.

Many civic and communal institutions are arrayed along the streets turning off from Barnet High Street. Another striking aspect is that the section of the high street south of the junction with Wood Street (the section running south-west), the site of St John the Baptist church today — and in the past myriad additional other town functions-marks a shift in both building scale and land use type, with a significantly larger number of small, independent shops and businesses. In addition, over the shops and in the rear of many plots are subsidiary businesses, such as printers. The character changes again at the point at which the street becomes the Great North Road. Each of these changes in land use and built form character are reflected in the distinctive spatial accessibility of the street segments in question, with the northernmost section of the high street being most dominant for trips at the local scale, and the southern sections being more central at the higher, $3000 \mathrm{~m}$ scale.

Further analyses of the relationship between the street network, built form and land use diversity can be seen in the series of images in Figure 9a-d, which trace the evolution of the section of the high street where it intersects with Wood Street, meeting at the site of St John's Church. All the buildings coloured up are listed in Figure 10, which shows all land uses listed in the relevant directories for the four epochs studied. Even without the statistical analysis of diversity (which we have reported elsewhere), it is evident that the mixing of commercial, retail, production, and service activities has remained apparent throughout the periods covered by the study [27]. 


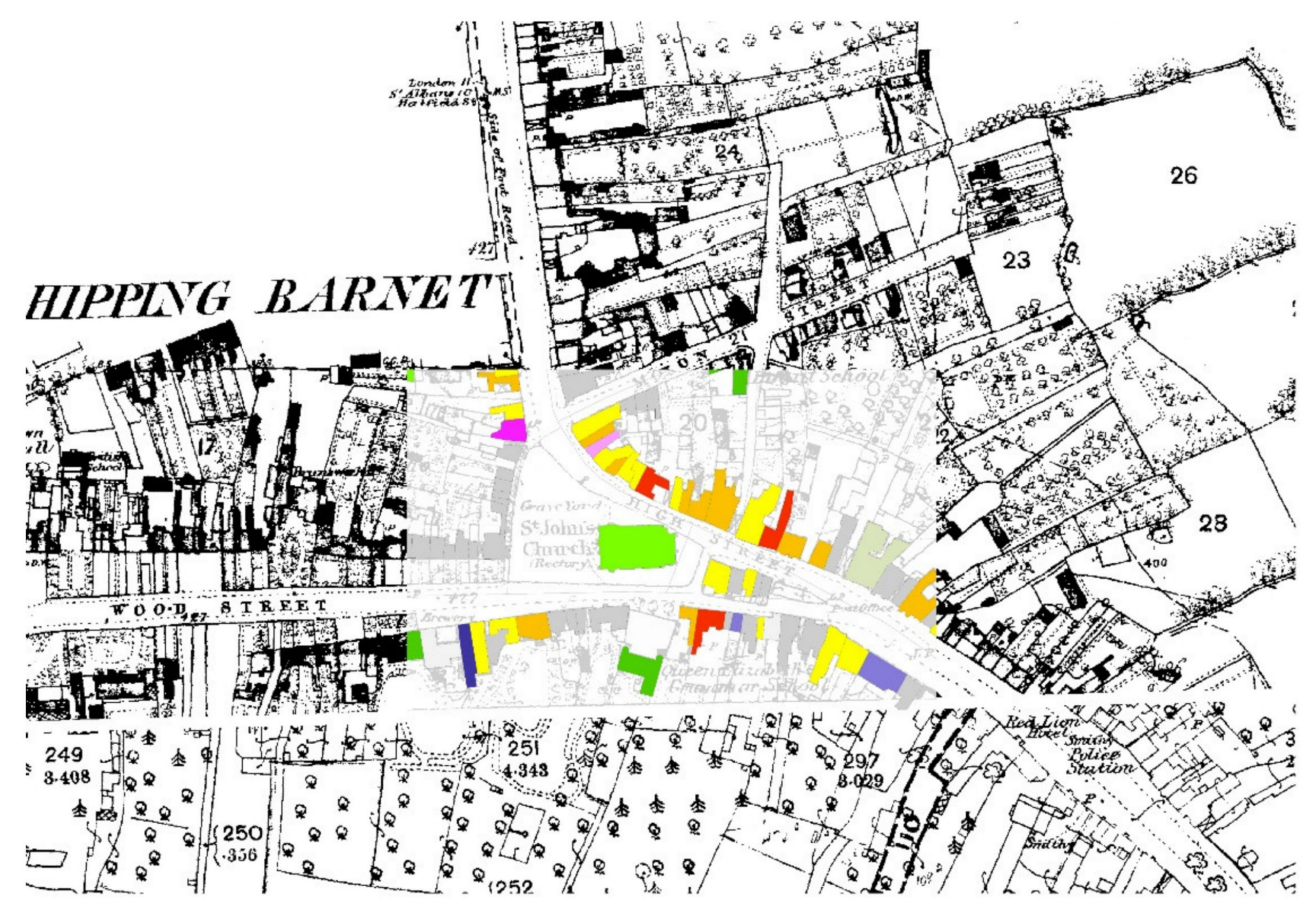

(a)

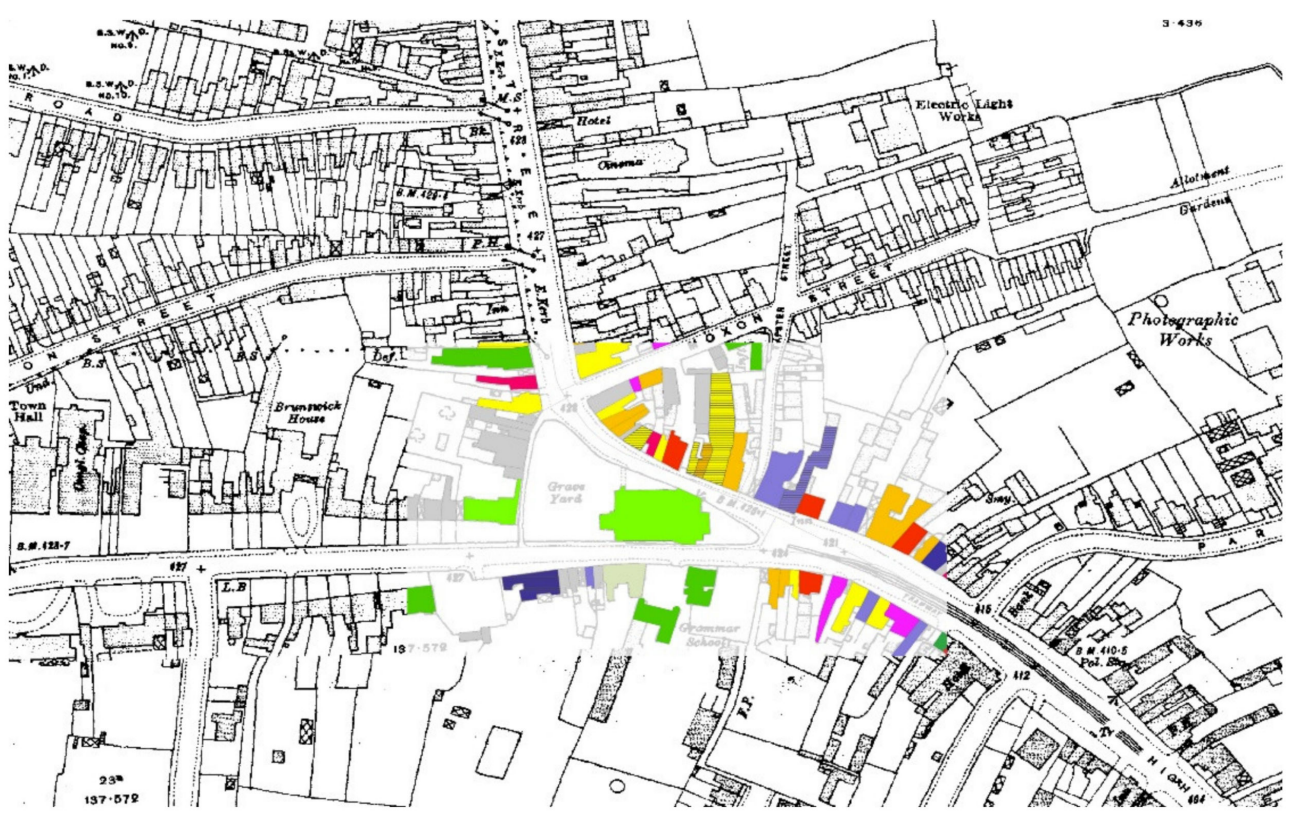

(b)

Figure 9. Cont. 


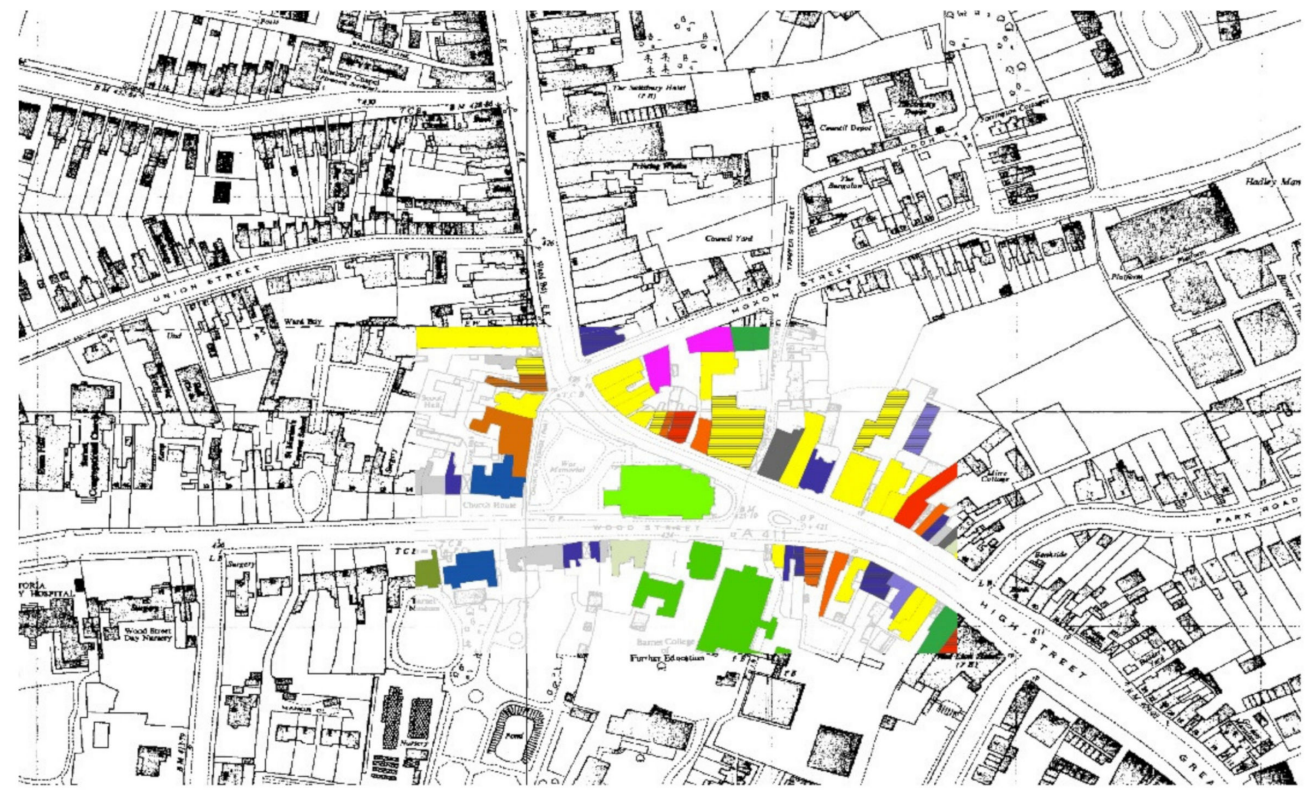

(c)

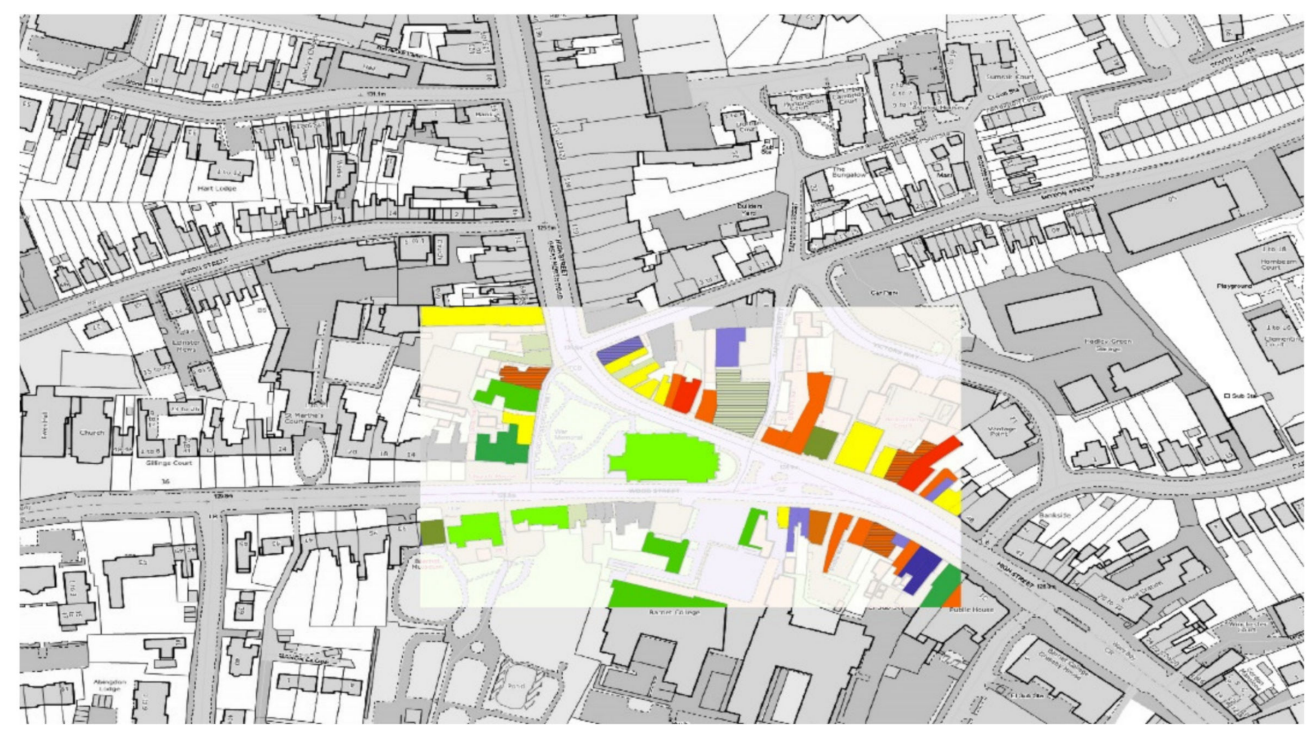

(d)

Figure 9. Land use diversity overlaid on contemporaneous map for (a) c. 1880, (b) c. 1910, (c) c. 1960, (d) 2013 @ Crown Copyright/database right 2013. An Ordnance Survey/EDINA supplied service. See Figure 8 for legend. 


\begin{tabular}{|c|c|c|c|}
\hline 1880 directory & 1910 directory & 1960 directory & 2013 directory \\
\hline West side of High Street (southwards) & West side of High Street (southwards) & West side of High Street (southwards) & West side of High Street (southwards) \\
\hline butcher & fancy repository & chernist & pharmacy \\
\hline \multirow[t]{6}{*}{ coach-buider } & chemist & employment agency & dentist \\
\hline & & office & restaurant \\
\hline & & bank & cafe \\
\hline & & newspaper press & charity shop \\
\hline & & ladies outfitters & Barnet Colege Hyde Institute (rear) \\
\hline & & betting office & skincare shop \\
\hline East side of High Street (southwards) & East side of High Street (southwards) & East side of High Street (southwards) & East side of High Street (southwards) \\
\hline baker & baker & fruiterer & travel agent (and above, recruitment agency) \\
\hline watch-maker & tailor & tents and camping shops & charity shop \\
\hline coal merchant & cycle maker & bakers & optician \\
\hline grocer & butcher & men's outfitters & second-hand clothing shop \\
\hline draper & butcher & pram shop & optician \\
\hline butcher & coal merchant's & confectioners & sweet shop \\
\hline The Old Kings Head public house & piano forte warehouse & cafe & restaurant \\
\hline baker & dairy & The King's Head public house & The King's Head public house \\
\hline boot-maker & The King's Head public house & cafe (Wimpey) & restaurant \\
\hline ironmonger & stationer & shoe shop & restaurant \\
\hline chemist & tobacconist & lingerie & alternative health centre \\
\hline stationer & baker & men's tailors & grocery store \\
\hline The Bull Inn & ironmonger & grocer (Tesco) & restaurant \\
\hline draper & lady's outfitter & Magistrate's Clerk's Office & bar \\
\hline watchmaker & draper & drapers & theatre \\
\hline The Mitre Inn & hairdresser & wine \& spirits merchant (Unwin's) & supermarket (Tesco) \\
\hline surgeon-dentist & stationer & boutique & bookmakers (Paddy Power) \\
\hline grocer & The Bull Inn & Ye Olde Mitre inn & restaurant (and above, secretarial college) \\
\hline \multirow[t]{6}{*}{ boot-maker } & draper & snack bar & Ye Olde Mitre Inn \\
\hline & dental surgeon & estate agent's & cafe \\
\hline & watch-maker & opticians & hairdresser \\
\hline & public house & & cloth shop \\
\hline & tobacconist & & phone shop \\
\hline & photographer & & \\
\hline \begin{tabular}{|l|} 
North side of Wood Street (eastwards) \\
\end{tabular} & North side of Wood Street (eastwards) & North side of Wood Street (eastwards) & North side of Wood Street (eastwards) \\
\hline $\begin{array}{l}\text { St John's Church } \\
\end{array}$ & Church Lad's brigade, Barnet Co. & solicitor's & Church House (hall) \\
\hline coffee rooms & St John's Church & Council Housing Department & St John the Baptist church \\
\hline baker & & St John the Baptist Church & \\
\hline South side of Wood Street (eastwards) & South side of Wood Street (eastwards) & South side of Wood Street (eastwards) & South side of Wood Street (eastwards) \\
\hline brewery & school & Barnet Museum & Barnet Museum \\
\hline Barnet County Court Office & solicitor \& commissioner for oaths & Barnet Council Offices & Barnet Council Offices \\
\hline carpenter & building society & accountant & Court House \\
\hline boot-maker & Barnet County Court Office & solicitor & orthopaedic clinic \\
\hline Queen Elizabeth Grammar School & carpenter & dentist & Barnet College \\
\hline tailor & doctor & South Herts./Barnet College of Further Education & \\
\hline photographer (same address as tailor) & Queen Elizabeth Grammar School & & \\
\hline \multicolumn{4}{|l|}{ Wood Street Public House } \\
\hline \multicolumn{4}{|l|}{ builder } \\
\hline \multirow{2}{*}{\multicolumn{4}{|c|}{ builder }} \\
\hline & & & general dealer \\
\hline ... continuing down High Street & ... continuing down High Street & ... continuing down High Street & -.. continuing down High Street \\
\hline wine merchant & tailor & tobacconists/confectioners (Macienzie's) & newsagent \\
\hline baker & tobacconist & estate agents & hairdresser \\
\hline house furnisher & ham \& beef shop & land surveyors & restaurant \\
\hline \multirow{9}{*}{ surgeon-dentst (same address as house furnisher) } & Crown \& Anchor inn & Crown \& Anchor bar & employment agency \\
\hline & harness manufacturer & cafe & cafe \\
\hline & baker & baker & funeral directors \\
\hline & auctioneers & building society (Ha ifax) & restaurant \\
\hline & confectioner & funeral drector's & insurance agency \\
\hline & mineral water manufacturer & hairdresser (rear or above) & estate agency \\
\hline & dentist & launderette & Barnet Conservative Club \\
\hline & Barnet \& District Constitutional Club & pianos & \\
\hline & & furniture sales & \\
\hline
\end{tabular}

Figure 10. Land uses at junction of High Street and Wood Street 1880-2013, with each street section compared across the four epochs.

The significant amount of persistence in types of land use is also apparent in Figure 10. Aside from the obvious example of the church, several pubs and institutions (marked in italics) have managed to maintain a presence over the 125 year period. Yet, it is equally clear that the buildings themselves have usefully adapted over time. Church House on Wood Street, for example, which in the 1920s and $30 \mathrm{~s}$ was regularly used by Church organisations. Subsequently, the building has been the home to Barnet Library; used by the military during World War II; and then as a venue for school meals. Today, it continues to serve a variety of community functions: from wedding receptions, to yoga, badminton, and theatre groups [38]. If we have learnt anything from our enquiry into the centuries-long history of London's suburbs, it is that suburban town centres are continually adapting to changing socio-economic and cultural norms. This suggests a dynamic, rather than static, definition of suburban heritage. Key to Barnet's legacy in this, spatial-morphological, sense is the configuration of its street network that serves to differentiate the stretch of Barnet High Street from the national highway of the Great North Road — of which it is a part. This has enabled relatively localised patterns of socio-economic activity in Barnet to benefit from more regionally extensive accessibility. 
Smaller buildings adapt generically, so a pub becomes a café, or a pharmacy becomes a health food shop. Small-scale production persists, such as the printer to the rear of Wood Street. Other buildings have been replaced with the same generic use. A good example of this is Barnet college, located on the junction of Wood Street and High Street Barnet, a short distance from High Barnet underground station, on the site that originally belonged to Queen Elizabeth's School founded in the sixteenth century (Figure 11). The Saturday Review of 1879 helpfully explains how the school had been recently revived from its 'neglected, half-ruinous' state, with the construction of a range of 'excellent school buildings, large playgrounds, and a headmaster's dwelling-house' to form a new grammar school. It benefited from 'easy access from London', so that ... 'instead of an unbroken silence, there is now, at due seasons, the bustle and stir of a very considerable school' [19].

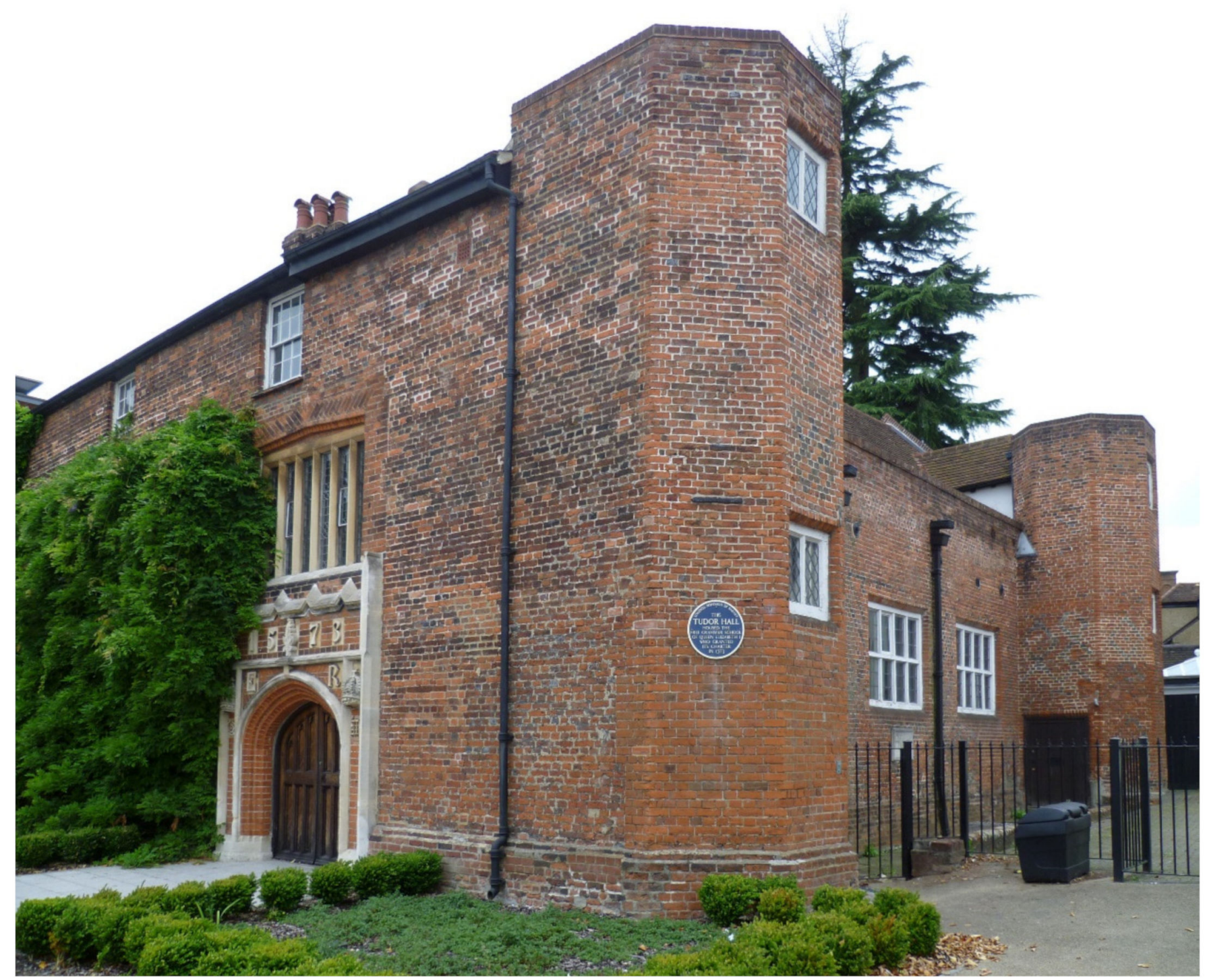

Figure 11. Original site of Queen Elizabeth's Grammar School, Barnet (now part of Barnet College), sited opposite St John's Church. The blue plaque states that 'This Tudor Hall housed the free grammar school of Queen Elizabeth I who granted its charter in 1573'. Photo by Philafrenzy, CC BY-SA 4.0, https:/ / commons.wikimedia.org/w /index.php?curid=51126572 (accessed on 4 October 2020).

\section{Discussion}

Our analysis has shown that Barnet's history as a suburban place constitutes a distinctive spatial-morphological heritage in relation to its immediate community, the surrounding 
counties and London. Its steady local growth over the centuries took a significant leap after the coming of the railway in the nineteenth century, which intensified building around the streets in its vicinity. Yet, the growth that resulted from this increase in global connectivity did not lead, as other of London's suburbs have suffered, to local severance by railway tracks, as the local train station was situated sufficiently outside of the main built-up area (and at a different topographical grade) to allow street connections to be maintained. This enduring spatial-morphological coherence has certainly helped to keep Barnet relatively intact as a centre of community. Another unexpected result of its pre-industrial era landscape has meant that the town's principal streets lie parallel to or away from the railway tracks, which means they are not quite as dominated by through traffic generated by the railway. As the business of retail has changed, the groups of shops with houses upstairs have been demolished, in some cases to make way for new enclosed shopping centres with parking attached. Interestingly, in the case of High Barnet, the creation of the roofed 'Spires' shopping mall improved the internal accessibility of the town centre, creating a new connection from the older part of settlement to its late nineteenth-century high street. In this context, one might reflect that such an intervention is consistent with Barnet's heritage as a localised 'deformation' of the Great North Road.

The changing nature of retail in Barnet also reflects demographic changes in the suburb. In Barnet, the effects of the incoming population post-World War II can be seen in the range of moderate to quite prosperous residences in the northern, more rural end of the town. Its demographic profile is, of course, influenced by proximity to London but this does not always result in traditional orientation of commuter journeys. For example, a young and socially diverse population travelling into the area to attend Barnet College, which was rebuilt and expanded in 2011, forming part of a regional consortium of schools. French makes a similar point in discussing community life in similarly peripheral nineteenthcentury Surbiton in south-west London. He argues that Surbiton was not place based in the sense of being geographically determined, as its residents did not belong to a single community [39].

In the case of Barnet, it is important to emphasise that we do not seek to identify a dominant representation of 'community heritage' in a suburban context. Rather, the spatial-morphological approach to heritage seeks to identify how a diverse and dynamic community life may be sustained by the patterns of everyday life, where it is possible that there is neither an explicitly shared nor a widely articulated sense of what that community actually means. We propose this has something to do with the way in which resilient suburban centres can bring people together in familiar relatively stable routines of spatial co-presence and encounter precisely without imposing a particular cultural idea. Indeed, the frequent accusations of the suburbs being banal is largely premised on the idea that conformity to the routine norms of everyday life allows significant scope for the fulfilment of personal aspiration.

We intend the spatial morphological approach developed here, therefore, to resonate with current thinking in heritage management and planning that emphasises how definitions of tangible built environment assets in terms of their community status are likely to be entangled with the 'intangible associations' of locality, including historical patterns of use [40]. An important consideration for us regards the notion of interface that define sociospatial relationships between different users and functional scales: for example between shop doors and windows and the street, between the side street and the high street, and between the configuration of accessible central streets and their residential hinterland [41]. Regarded as a characteristic patterning of interfaces the suburban streetscape is realised not simply a static setting for this or that heritage object but as strongly implicated in the construction of the heritage asset itself, as part of a living community. The mapping of key interfaces that define the meaningful social space of community heritage, connecting the micro-morphological to larger scales of movement, contributes an important layer of description to assist in the definition, management and protection of everyday heritage. 
It is true that such a spatio-morphological approach to heritage must acknowledge a degree of fluidity in its definition. This is because the status of tangible heritage is said to be at least partially contingent on the intangible associations arising from its historical embedding in everyday social practices that are likely change over time consistent with prevailing socio-economic and cultural norms. Even so, any assessment of broader heritage contexts can only benefit from engaging with a spatial-morphological approach which balances a necessary sensitivity to material or aesthetic dimensions with a specific focus on its role in constituting social identities, particularly within local communities. Yet, as we have shown in the case of Chipping Barnet, this fluidity should not be overstated since a key contribution of the spatial-morphological approach is to express how social meanings are constructed through the materiality of an historical built environment that is characterised by continuity as well as change. The point then, is less to relativise heritage to the point when it becomes indistinguishable from the shifting practices of everyday life, so much as to explain how heritage management that aspires to protect the heritage of living communities can benefit by engaging with the spatial-morphological description of arrangements of streets and buildings that sustain their identities as places.

London's suburban periphery continues to be a highly dynamic environment, comprising diverse spatial morphologies, topographies and socio-economic structures. Our case study of Chipping Barnet has shown how old spaces were re-used, adapted and modified in new ways, without, necessarily entirely displacing previous patterns of activity-and rarely all at once. This has important implications for understanding what a 'suburb' is and is not. By focusing on the spatial morphology of Barnet as a starting point, the idea of place is shown both to be less stable than traditional local histories can imply-but also not something that can be said to be eradicated simply because many people commute from there to work in London. Similarly, Barnet's continuing vitality can be, at least partially, attributed to the long-term adaptability of the historical street network and the wide array of smaller and larger premises this helps to support. Easy access between the commercial activity along the high street and other town centre activities, such as the library, museum and local college is a vital aspect of how Barnet works today. Moreover, looking beyond the tarmacked streets lined by somewhat prosaic building facades reveals traces of past activities not only in the buildings and land uses, but also in the properties of the network itself. For example, the extent to which pedestrian footpaths establish the high street as the centre for movement flows at a walkable distance from the centre's residential hinterland. Barnet is characterised not only as a place that means things to people who live there but also as something that is done in a corporeal sense, involving the comings and goings of daily life making use of the affordances of a spatial morphology with its origins in medieval England and its most recent elements less than half a century old. While these two aspects of its spatial culture are distinct, neither can they be entirely separated. They describe the dialogue of tangible and intangible aspects of suburban community heritage that serve to remind us that however potent and negotiable cultural images of the suburbs may be, they do not suffice to understand what is at issue in the description and delineation of their heritage as communities.

Author Contributions: Conceptualisation, methodology, analysis, writing, and visualisation were a team effort by the authors. Writing — original draft, L.V. and S.G.; Writing - review \& editing, L.V. and S.G. Both authors have read and agreed to the published version of the manuscript.

Funding: This paper draws on research funded by the UK Engineering and Physical Sciences Research Council (EPSRC). Reference: EP/I001212/1. Title: Adaptable Suburbs: a study of the relationship between networks of human activity and the changing form of urban and suburban centres through time.

Data Availability Statement: Land use data may be obtained from the authors.

Acknowledgments: We are grateful to colleagues on the Adaptable Suburbs project, whose earlier contributions fed into the analysis reported on in this paper. 
Conflicts of Interest: The authors declare no conflict of interest.

\section{References}

1. Ackroyd, P. London: The Biography; Chatto \& Windus: London, UK, 2000.

2. Webster, R. Expanding Suburbia: Reviewing Suburban Narratives; Berghahn Books: New York, NY, USA, 2000.

3. Vaughan, L.; Griffiths, S.; Haklay, M.; Jones, C.E. Do the suburbs exist? Discovering complexity and specificity in suburban built form. Trans. Inst. Br. Geogr. 2009, 34, 475-488. [CrossRef]

4. Palaiologou, G.; Larimian, T.; Vaughan, L. The Use of Morphological Description in Neighbourhood Planning: Form-based Assessment of Physical Character and Design Codes. J. Urban. 2020, 1-25. [CrossRef]

5. Mosler, S. Everyday heritage concept as an approach to place-making process in the urban landscape. J. Urban Des. 2019, 24, 778-793. [CrossRef]

6. UNESCO. Recommendation on the Historic Urban Landscape, Including a Glossary of Definitions. Available online: http: / / portal.unesco.org/en/ev.php-URL_ID=48857\&URL_DO=DO_TOPIC\&URL_SECTION=201.html (accessed on 12 May 2021).

7. Kong, Y.; Karimi, K. Exploration of urban heritage in the historic core of London: A spatial network approach. In Proceedings of the 12 International Space Syntax Symposium, Beijing, China, 12-18 June 2019; pp. 1-13.

8. Hillier, B.; Hanson, J. The Social Logic of Space; CUP: Cambridge, UK, 1984.

9. Karimi, K. Urban conservation and spatial transformation: Preserving the fragments or maintaining the 'spatial spirit'. Urban Des. Int. 2020, 5, 221-231. [CrossRef]

10. Hillier, B. Centrality as a Process: Accounting for Attraction Inequalities in Deformed Grids'. Urban Des. Int. 1999, 4, 107-127. [CrossRef]

11. Hebbert, M. The Street as Locus of Collective Memory. Environ. Plan. D Soc. Space 2005, 23, 581-596. [CrossRef]

12. Griffiths, S. Chapter 2: The High Street as a Morphological Event. In Suburban Urbanities: Suburbs and the Life of the High Street; Vaughan, L., Ed.; UCL Press: London, UK, 2015; pp. 32-50.

13. Palaiologou, G.; Griffiths, S. The Uses of Space Syntax Historical Research for Policy Development in Heritage Urbanism. In Cultural Urban Heritage; Obad Šćitaroci, M., Bojanić Obad Šćitaroci, B., Mrđa, A., Eds.; Springer: Cham, Switzerland, 2019. [CrossRef]

14. Hillier, B. The architecture of the urban object. Ekistics 1989, 56, 5-21.

15. Slater, T.R. Planning English Medieval 'Street Towns': The Hertfordshire Evidence. Landsc. Hist. 2004, 26, 23. [CrossRef]

16. Griffiths, S.; Jones, C.E.; Vaughan, L.; Haklay, M. The persistence of suburban centres in Greater London: Combining Conzenian and space syntax approaches. Urban Morphol. 2010, 14, 85-99.

17. Slater, T.R. Chapter 4: Roads, Commons and Boundaries in the Topography of Hertfordshire Towns. In A County of Small Towns: The Development of Hertfordshire's Urban Landscape to 1800; Terry, R.S., Nigel, G., Eds.; Hertfordshire Publications: Hatfield, UK, 2008; pp. 67-95.

18. Taylor, S.P. Chapter 11: Boundaries, Margins and the Delineation of the Urban: The Case of Barnet. In A County of Small Towns: The Development of Hertfordshire's Urban Landscape to 1800; Slater, T.R., Goose, N., Eds.; Hertfordshire Publications: Hatfield, UK, 2008; pp. 249-275.

19. Saturday Review. Barnet and Its Grammar School. In Saturday Review of Politics, Literature, Science and Art; Parker, J.W.S., Ed.; 1879; pp. 491-492. Available online: https://books.google.com.hk/books/about/The_Saturday_Review_of_Politics_Literatu. html?id=e909AQAAIAAJ\&redir_esc=y (accessed on 10 June 2021).

20. Chartres, J.A. The Capital's Provincial Eyes: London's Inns in the Early Eighteenth Century. Lond. J. 1977, 3, 30. [CrossRef]

21. Pepys, S. The Diary of Samuel Pepys. Vol. 8, 1667; Latham, R., Matthews, W., Eds.; HarperCollins: London, UK, 2016.

22. Jones, P.; Roberts, M.; Morris, L. Rediscovering Mixed-Use Streets: The Contribution of Local High Streets to Sustainable Communities; Joseph Rowntree Foundation \& Polity Press: London, UK, 2007.

23. Cary, J. Cary's Survey of the High Roads from London to Hampton Court Richmond. On a Scale of One Inch to a Mile To Which Is Added the Number of Inns on Each Separate Route Also, the Different Turnpike Gates; Engraver \& Map Seller: London, UK, 1790.

24. Griffiths, S.; Palaiologou, G. Place-Situated Historic Photographs in European Cities: Negotiating the Temporal Boundaries of Urban Community. In Urban History Group Annual Conference: Boundaries and Jurisdictions-Defining the Urban; Royal Holloway College, University of London: London, UK, 2017.

25. Griffiths, S.; von Lünen, A. Spatial Cultures: Towards a New Social Morphology of Cities Past and Present; Routledge: London, UK, 2016.

26. Dhanani, A. Chapter 3: Suburban Continuity and Change. In Suburban Urbanities; Vaughan, L., Ed.; UCL Press: London, UK, 2015; pp. 53-76.

27. Vaughan, L.; Jones, C.E.; Griffiths, S.; Haklay, M. The Spatial Signature of Suburban Town Centres. J. Space Syntax 2010, 1, 77-91.

28. Whitehand, J.W.R. British Urban Morphology: The Conzenian tradition. Urban Morphol. 2001, 5, $103-109$.

29. Griffiths, S.; Vaughan, L. Mapping spatial cultures: Contributions of space syntax to research in the urban history of the nineteenth-century city. Urban Hist. 2020, 47, 488-511. [CrossRef]

30. De Certeau, M. The Practice of Everyday Life (Trans. Steven Rendall); University of California Press: Berkeley, CA, USA, 1984; p. 117.

31. Bingham-Hall, J.; Law, S. Connected or informed?: Local Twitter networking in a London neighbourhood. Big Data Soc. 2015, 2, 2053951715597457. [CrossRef] 
32. Dhanani, A. Street Network Centrality and Built Form Evolution in the Spatial Development of London's Periphery 1880-2013; University College London: London, UK, 2014.

33. Hillier, B. The City as a Socio-Technical System: A Spatial Reformulation in the Light of the Levels Problem and the Parallel Problem. In Digital Urban Planning and Modelling; Müller, S., Ed.; Springer Communications in Computer and Information Science; Springer: Berlin, Germany, 2009.

34. Hillier, B. Spatial Sustainability in Cities: Organic Patterns and Sustainable Forms. In Seventh International Space Syntax Symposium; Koch, D., Marcus, L., Steen, J., Eds.; Royal Institute of Technology: Stockholm, Sweden, 2009.

35. Hillier, B.; Vaughan, L. The City as One Thing. Prog. Plan. 2007, 67, 205-230.

36. Geddes, I.; Vaughan, L. Why Do People Walk in the Suburbs? An Analysis of How Spatial Configuration and Land Use Diversity Contribute to Walkability; University College London: London, UK, 2014.

37. Conisbee, M.; Kjell, P.; Oram, J. Clone Town Britain: The Loss of Local Identity on the Nation's High Streets; New Economics Foundation: London, UK, 2004.

38. Information from the Church House, Barnet Website. Available online: http://www.churchhousebarnet.co.uk. (accessed on 15 June 2021).

39. French, C. The Good Life in Victorian and Edwardian Surbiton: Creating a Suburban Community before 1914. Fam. Community Hist. 2011, 14, 110. [CrossRef]

40. Historic England. The Setting of Heritage Assets: Historic Environment Good Practice Advice in Planning Note 3, 2nd ed.; 2017, pp. 10-11. Available online: https://historicengland.org.uk/images-books/publications/gpa3-setting-of-heritage-assets/heag1 80-gpa3-setting-heritage-assets / (accessed on 15 June 2021).

41. Palaiologou, G.; Griffiths, S.; Vaughan, L. Reclaiming the virtual community for spatial cultures: Functional generality and cultural specificity at the interface of building and street. J. Space Syntax 2016, 7, 25-54. 